\title{
Potential of unsubsidized distributed solar PV to replace coal-fired power plants, and profits classification in Chinese cities
}

\author{
Ying Yang ${ }^{a, *}$, Pietro Elia Campana ${ }^{\mathrm{a}, \mathrm{b}}$, Jinyue Yan ${ }^{\mathrm{a}, \mathrm{b}, * *}$ \\ ${ }^{a}$ School of Business, Society \& Engineering, Mälardalen University, Västerås, 72123, Sweden \\ ${ }^{\mathrm{b}}$ Department of Chemical Engineering, KTH Royal Institute of Technology, Stockholm, 10044, Sweden
}

\section{A R T I C L E I N F O}

\section{Keywords:}

Distributed solar photovoltaic

Zero subsidies

Cost-risk

Investment-profit

Crossover math

K-means clustering algorithm

\begin{abstract}
A B S T R A C T
This paper analyzes if solar photovoltaic technology is economically feasible enough to compete with coal-fired power in Chinese cities in the subsidy-free context. Considering this, this paper further investigates how profitable investing in solar PV projects is. This paper firstly analyzes to what degree local coal-fired power plants can be replaced by distributed solar power in 344 prefectural-level cities in China. Levelized Cost of Electricity of solar PV power and the local desulfurized coal benchmark price are used for simplified cost crossover math to identify the replacement risk of local coal-fired power plants. Four risk-levels and their corresponding cities are identified, i.e. deemed no cost-risk, potentially at cost-risk, at cost-risk, and substantially at cost-risk. As a whole, $85.17 \%$ of current coal-fired power plants from the investigated cities are under cost-risk. Levelized Profit of Electricity, Net Present Value, Internal Rate of Return, and Discounted Payback Period are calculated for each city, and grouped using K-means algorithm. The cities are clustered into four groups, i.e. high return, medium return, moderate return, and low return. The results show that $65.99 \%$ of all the cities could achieve a moderate or higher financial return. The cost-risk and investment profit results are mapped for a better understanding of the regional variation in China.
\end{abstract}

\section{Introduction}

Currently, $75 \%$ of electric power in China, as a pillar of the economy, still heavily depends on coal-fired power plants [1]. The rapid development of the Chinese economy will demand massive electricity consumption in the future. As indicated by statistics in 2015, 38\% of $\mathrm{SO}_{2}$ and $42 \%$ of $\mathrm{NO}_{\mathrm{x}}$ (among total emissions) were produced from coal-fired power generation [1], and $40 \%$ of total carbon emissions were contributed from coal combustion [2]. Apart from the significant air pollution and greenhouse gas emissions, the following are also becoming major constraints on sustainable economic development: water pollution, noise pollution, and the pressure on water resources [3]. Solar photovoltaic (PV), as a budding new energy technology, has received intensely growing interest, both from academia and from industry. Because of the maturity of the technology and its declining costs, solar PV power production has been acknowledged as a promising technology with the potential to replace coal-fired power generation [4]. China has formulated a target of $15 \%$ non-fossil primary energy by 2020 , and recently announced another ambitious target of $20 \%$ non-fossil primary energy by 2030 [5]. Solar energy is certainly a promising contributor and a strategically important technology for realizing these targets.

Distributed solar PV projects have been expanding since 2013, mostly because of incentives created by the policy "Notice to play the role of the leverage of electricity tariff to promote the healthy development of solar $P V$ industry" on August 30th, by National Development and Reform Commission (NDRC) [6]. This policy allowed distributed solar PV projects to receive a $0.42 \mathrm{CNY} / \mathrm{kWh}$ Feed-in Tariff (FIT). Since then, Distributed Generation (DG) projects have enjoyed policy support for fifteen years from the central government in the form of FIT, demonstration projects [7], and free grid-connection services [8]. Furthermore, local governments are encouraged to provide matching financial subsidies based on national subsidies [9]. Financial aid from local governments-in the form of cheap loans, tax breaks, low-cost land-use rights, and subsidized electricity-makes investment in solar PV more attractive, at times even sending the market into a 'feverish frenzy' [10]. More and more DG projects are being built in cities, e.g. residential buildings, commercial buildings, industrial buildings, public utilities (e. g. roads, schools, hospitals, stations, airports, and parks). In response to these incentives, China's domestic DG PV market has seen steady

\footnotetext{
* Corresponding author.

** Corresponding author. School of Business, Society \& Engineering, Mälardalen University, Västerås, 72123, Sweden.

E-mail addresses: ying.yang@mdh.se, ying.yang@mdh.se (Y. Yang), jinyue@kth.se (J. Yan).
} 


\begin{tabular}{|c|c|c|c|}
\hline \multicolumn{2}{|c|}{ Abbreviations } & \multicolumn{2}{|l|}{ Symbols } \\
\hline & & $\mathrm{k}$ & the $k^{\text {th }}$ cluster, $\mathrm{k}=1,2, \ldots, 4$ \\
\hline PV & Photovoltaic & $C_{1}^{(1)}$ & the center for initial cluster 1 \\
\hline FIT & Feed-in Tariff & $C_{2}^{(1)}$ & the center for initial cluster 2 \\
\hline NDRC & National Development and Reform Commission & $C_{3}^{(1)}$ & the center for initial cluster 3 \\
\hline NEA & National Energy Administration & $C_{4}^{(1)}$ & the center for initial cluster 4 \\
\hline LCOE & Levelized Cost of Electricity & $\mathrm{d}(\mathrm{p}, \mathrm{q})$ & the Euclidean Distance \\
\hline DCB & Desulfurized coal benchmark & $\mathrm{m}(\mathrm{p}, \mathrm{q})$ & the Mahalanobis Distance \\
\hline LPOE & Levelized Profit of Electricity & $x_{p i,} x_{q i}$ & Dimension (i.e. LPOE, NPV, IRR, and DPBP) value of a city, \\
\hline NPV & Net Present Value & & $\mathrm{p}=1,2, \ldots, 344, q=1,2, \ldots, 344 . \mathrm{i}$ is the dimension, $\mathrm{i}=$ \\
\hline IRR & Internal Rate of Return & & $1,2,3,4$ \\
\hline DPBP & Discounted Payback Period & $a, b$ & the $a^{\text {th }}$ and $b^{\text {th }}$ iteration $(\mathrm{a} \neq \mathrm{b})$ \\
\hline GIS & Geographic Information System & $c_{k}^{(a)}, c_{k}^{(b)}$ & the cluster $\mathrm{k}$ at $a^{\text {th }}$ or $b^{\text {th }}$ iteration \\
\hline ANOVA & Analysis of Variance & $c_{k}, c_{k}$ & \\
\hline SCR & Self-consumption rate & & \\
\hline
\end{tabular}

growth, with its cumulative installed capacity rising from $3.10 \mathrm{GW}$ in 2013 to $4.67 \mathrm{GW}$ in 2014 , to $29.66 \mathrm{GW}$ in 2017 , then surging to 50.61 GW by the end of 2018 [11]. The newly installed DG capacity across different provinces by the end of 2018 is shown in Fig. 1. Noticeably, solar resources vary regionally across China. The solar resources in the northwest are much more abundant than in the southeast. Nevertheless, actual installations of distributed solar PV are concentrated in the southeast, because of the vastly greater availability of rooftop spaces.

Compared with large-scale solar PV projects, Distributed Generation is a key solution for energy provision in urban areas, given its smaller scale relative to utility-scale projects, higher efficiency, and higher penetration rates. Recently, DG investment costs are being significantly driven down through technological innovations and economies of scale (Fig. 2).

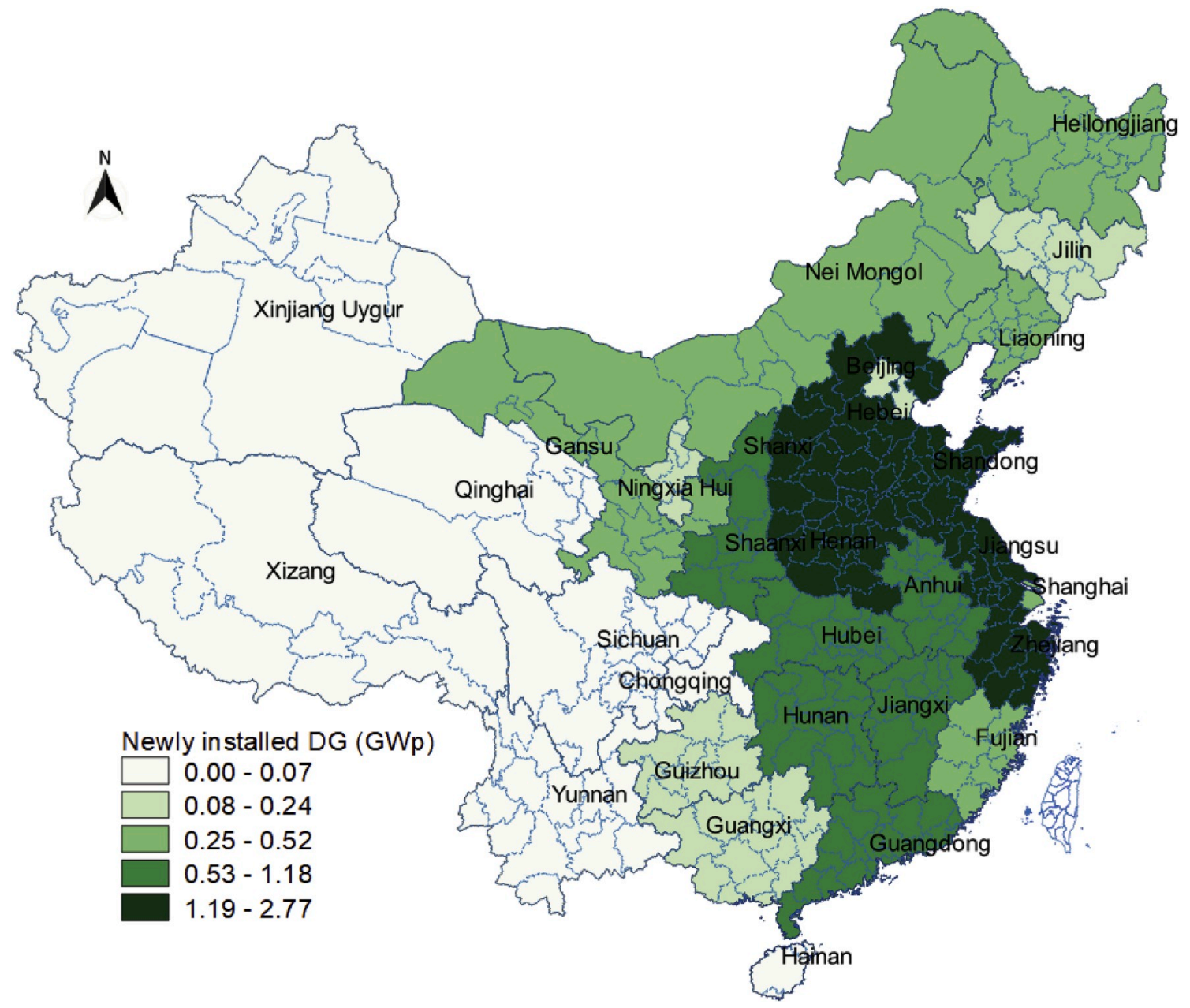

Fig. 1. The newly installed distributed project capacity across provinces by the end of 2018. The blue dashed lines represent the boundaries of prefectural-level cities. (For interpretation of the references to colour in this figure legend, the reader is referred to the Web version of this article.) 


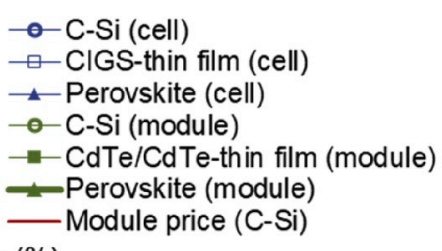

Efficiency (\%)

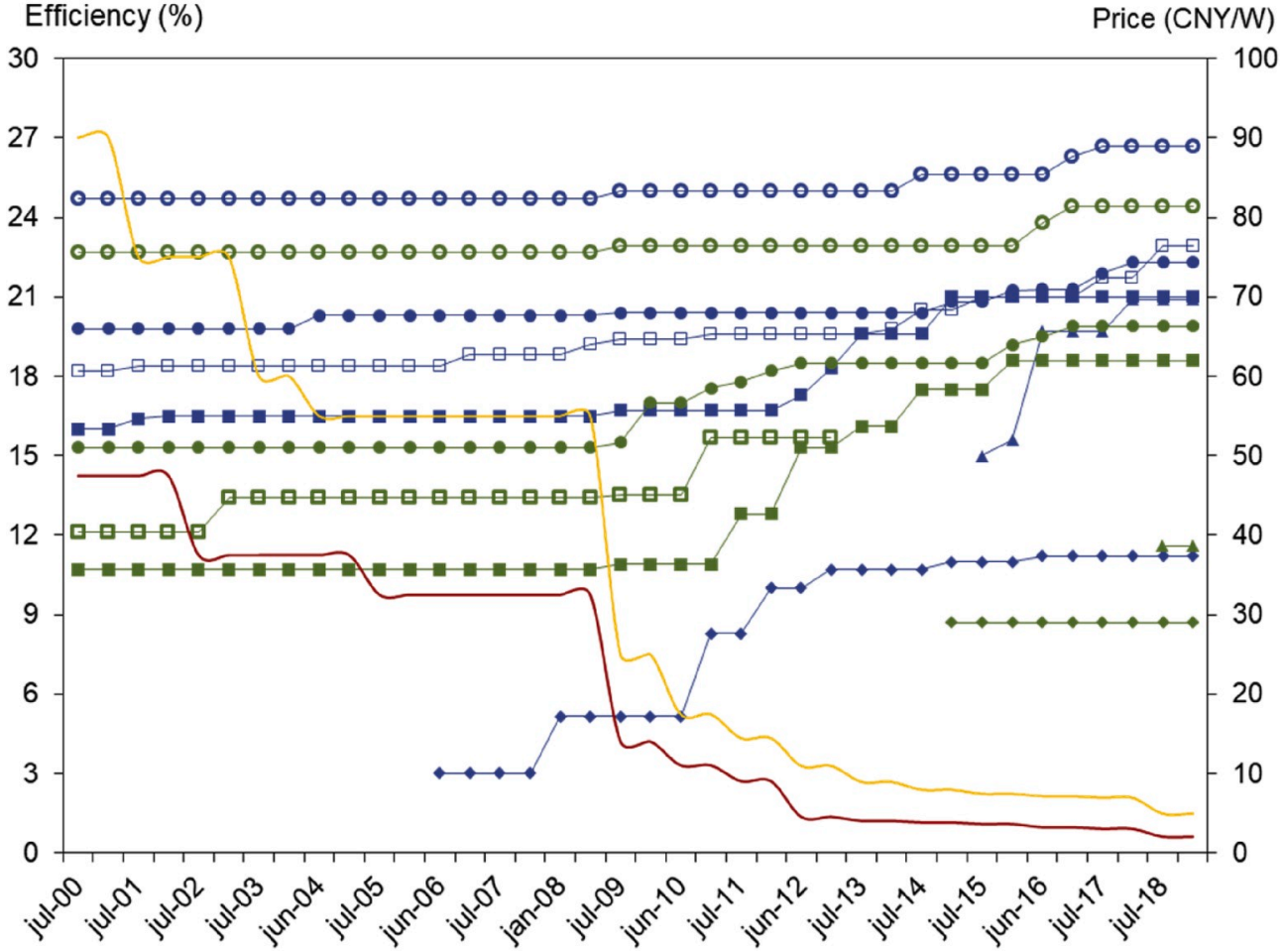

System price (grid-connected) Price (CNYM)

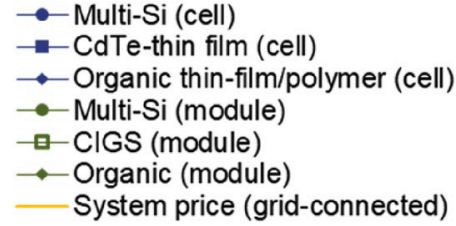

Fig. 2. Solar cell and module efficiency improvement and driven-down costs (Data from Ref. [12,13]).

In Fig. 2, the blue and green lines with markers represent the current state-of-the-art solar technologies' efficiencies, as reported from recognized test centers. Among these, the blue lines represent solar cell efficiencies which were best reported for "one-sun" (non-concentrator) single-junction cells and submodules. The green lines represent solar module efficiencies. They were both measured under the global AM1.5 spectrum $\left(1000 \mathrm{~W} / \mathrm{m}^{2}\right)$ at $25{ }^{\circ} \mathrm{C}$ [12]. The markers represent different technologies, including: crystalline silicon, multi-crystalline silicon, CIGS (CuInGaSe2), CIGS thin-film, CdTe, CdTe thin-film, perovskite, organic, and organic thin-film/polymer. The lines without markers (orange) represent Chinese solar $\mathrm{C}-\mathrm{Si}$ module prices and system prices [13]. Note: $1 \mathrm{CNY}=7.08$ USD (on Aug. 23, 2019).

China's energy consumption, unlike that of developed countries (for instance, Germany and Spain), is growing rapidly. There are still pressures on energy provision, fossil fuel replacement, and pollution mitigation. The Chinese government has been making substantial efforts on the development of renewable energy, such as solar PV [13]. Phase-out of coal-fired power is by no means a unanimous call. Significant amount of literature studied the technological advances and social equity on replacing coal by solar electricity. But little effort has been made on economic competitiveness and affordability in city-level, especially in large-scale Chinese cities.

This paper studies two main problems: (1) Are China's photovoltaic projects generally economically competitive enough with traditional coal-fired power generation? (2) How investment profits would differ from city to city in the context of subsidy-free. This study combines a Levelized Cost of Electricity (LCOE) dataset and a local desulfurized coal benchmark price dataset in order to present simplified cost crossover math. Four cost-risk levels and their corresponding cities are identified, i.e. "deemed no risk", "potentially at risk", "at risk", and "substantially at risk". This risk analysis considers both technical aspects and market aspects. In addition, this paper uses the K-means clustering algorithm to group 344 prefectural-level Chinese cities into four investment-profit dimensions. This study considers local resource endowments (represented by PV power generation) and local economic conditions (represented by electricity market price and DCB price) to calculate the economic attributes for the assessment. Four city groups were identified according to different profit levels, i.e. cities of "high return", "medium return", "moderate return", and "low return".

This paper is organized as follows. Section 1 is the introduction and background. Section 2 provides the literature review. Section 3 describes the methodology of the crossover algorithm and the K-means clustering algorithm. Section 4 presents the results. Section 5 presents the discussions. Section 6 draws the conclusions.

\section{Literature review}

Financial subsidies from governments have long played one of the most critical roles in solar PV industry. However, more concerns will follow the burgeoning of the distributed solar PV industry. The industry's future developments may be affected by overinvestment, overcapacity, and singular short-term focus [13]. Over-enthusiastic investments prevent technological innovations and technology efficiency improvements. This hinders the development of leading enterprises and of the whole solar PV industry [14]. Regarding subsidy policies as the main reason, some researchers have even testified that China's PV industry investment policy has had no positive effect [15]. Others have agreed that when the distributed PV industry develops to a certain stage, financial subsidies should be gradually reduced [8]. The government should moderately reduce subsidy intensity, and make the 
market play a pivotal role in the allocation of resources. Through price ladder leverage and certain market forces, the economic efficiency of distributed PV projects can also be great. Solar PV incentives should be structured to encourage a transition to subsidy-free.

In practice, there has also been a significant signal from the central government, which implies the subsidies from the central government will be continuously scaled down and even cut off. The so-called "531 New Policy" accelerated the reduction of solar PV industry financial incentives, and emphasized the need to transition China's solar industry from quantity-oriented to quality-oriented development [16]. In fact, the new policy issued on January 2019 by NDRC and National Energy Administration (NEA) [17] clearly pointed out that the cost of photovoltaic power generation has reached grid parity in areas with good solar radiation, low construction costs, well-established investment schemes, and favorable market conditions. Besides, from our previous study [18], solar PV generation prices in all the investigated cities have reached parity with electricity market prices. And in some cities, solar PV generation prices have reached parity with desulfurized coal benchmark (DCB) prices without state subsidies. This is the transition point for Chinese solar PV projects entering the market with zero subsidies.

However, the removal or tapering down of state subsidies would depress the prices of solar PV systems [19]. While planning the transition from coal-fired power to green power, it is common to consider primarily cost. It is worthy of comparing the cost of unsubsidized solar PV power and coal-fired power, in order to achieve the goal of transition. Previous studies made useful attempts from technical and social perspective. Figueiredo et al. [20] explored the impact of replacing coal-fired generation by photovoltaics from the Portuguese electricity system. The authors studied three scenarios and provided the deployed PV capacity correspondingly. Leonard et al. [21] studied the solar and wind rated power to substitute part or all the coal-fired power. These studies, from the perspective of capacity requirements, outlined a possible path for the phase-out of coal-fired power plants. Chapman et al. [22] pointed out that replacement of coal plants with solar PV plants would benefit lower income households more than wind, from the perspective of job provision. Lee et al. [23] estimated consumers' willingness to pay for phase-out coal sources generation with renewable energy, such as solar PV, in South Korea. Prehoda and Pearce [24] explored the impact of coal-fired power plants to solar PV on mortality. The results showed over 51,000 lives/year could be saved in the US, which made clear large-scale PV deployment could help solve public health problem and justices. These studies focused on the social equity and social environment in the retirement and replacement of coal-fired power plants. But limited attention was put on the analysis of cost competitiveness.

The absence of state subsidies is expected to reshuffle the solar power industry: only the most technologically advanced and cost-efficient enterprises will thrive. This will impose considerable pressure on the overall solar PV industry. Investments and entrepreneurs may change their behaviors due to uncertainties in the policy and investment environment. Among other types of renewable energy, investment evaluation of solar PV power generation in China has not gained much attention or deep analysis [25]. Some researchers have studied the cost-profit of Chinese solar PV projects. However, they focused on either a single solar PV project/system in a present scenario [26], or a future scenario for various cities [27]. Current research took government subsidies as a default parameter when evaluating investment [27]. Nevertheless, there is a lack of comprehensive studies analyzing the investment potential of distributed solar PV projects across China's cities, especially in the context of zero subsidies scenarios. Based on our previous study [18], this study seeks to take the analysis a step further, by analyzing the different levels of investment potential in different cities.

As tools, clustering techniques are used to find distinctive groups of profiles. Clustering is an effective tool for analyzing static data or time- series data, such as electricity usage. Researchers use electricity data to cluster, e.g. public sector, services, agriculture, residential, commercial, and industrial consumers in different locations, e.g. Italy, South Korea, California, Finland, and China. Chicco [28] and Kim et al. [29] mainly explored effective and optimal clustering techniques in determining typical load profiles. Kwac et al. [30], Räsänen et al. [31], and Zhou et al. [32] mainly analyzed electricity consumption profiles among different consumers, and forecasted load. J.D. Rhodes et al. [33] explored the drivers behind the derived groups of electricity customers.

Our previous study [18] analyzed the costs and profits of investing in distributed solar PV projects in current Chinese cities, based on the context of zero subsidies. According to results, all 344 cities in our statistical sample can reach $100 \%$ user-side grid parity, and $22.09 \%$ can reach plant-side grid parity. This paper further explores: firstly, the possibility of currently running coal plants being replaced by subsidy-free solar PV projects, and secondly, the different levels of investment returns. The overall aim of this study is to evaluate the competitiveness with coal and affordability of solar PV electricity without any subsidies.

\section{Methodology and data}

The methodology, data input used in this paper and output are shown in Fig. 3. Our previous study [18] prepared the essential data (the first step) for the analysis in this paper. First, the system scheme- such as technical assumptions-is specified. Through Meteonorm ${ }^{\circledR}$ and MATLAB ${ }^{\circledR}$ software, the distributed solar PV system yearly power generation in 344 prefectural-level cities is calculated. The selected economic parameters-i.e. LCOE, Levelized Profit of Electricity (LPOE), Net Present Value (NPV), Internal Rate of Return (IRR), and Discounted Payback Period (DPBP) - are calculated based on annual power generation, investment costs, operation \& maintenance costs, and market prices. Second, the DCB price to solar PV cost crossover analysis is conducted. Four coal cost-risk levels are recognized. Third, by employing the K-means clustering algorithm, the 344 prefectural-level cities are clustered into four groups according to their investment-profit levels. Furthermore, the coal cost-risks and solar PV investment-profits related results are illustrated based on Geographic Information System (GIS) software QGIS ${ }^{\circledR}$. Section 3.1 and section 3.2 explain the methodologies and data in detail.

\subsection{Desulfurized coal benchmark price to Distributed Generation cost crossover}

The system, technical assumptions, and economic parameters follow our previous study [18]. In this paper, a 1-MW distributed system that covers an area of $10,000 \mathrm{~m} 2$ is studied. The latitude of the location as the optimal tilt angle is used [34]. The system specifications are assumed based on the current literature: $98 \%$ inverter efficiency at rated power [35], $2 \%$ soiling losses [36], 90\% Balance-of-System efficiency [37], $10 \%$ ground reflectance [38], 17.1\% PV module efficiency [39], and $0.3 \%$ year PV module ageing factor [40]. The latitude and longitude data of 344 cities were extracted from Google Maps. The meteorological data, including global horizontal radiation, diffuse horizontal radiation, ambient temperature, and wind speed at $10 \mathrm{~m}$ height, were obtained from Meteonorm ${ }^{\circledR}$ [41]. The annual solar electricity generation was calculated using MATLAB ${ }^{\circledR}$ software. With these assumptions and data, the distributed solar PV annual electricity production in 344 cities are shown in Fig. 4 below.

The system investment costs for the distributed solar PV whole life cycle are divided into three parts: initial investment costs, inverter replacement in the 10th year, and operation \& maintenance costs. The initial investment costs include: 1) photovoltaic modules; 2) supporters; 3) inverter; 4) wirings; 5) engineering/labor costs; 6) junction boxes; 7) insurance costs; 8) grid connection fee; 9) five-year roof rent for initial investment, and; 10) bank loan interest rate. The costs in 1) to 8) are 


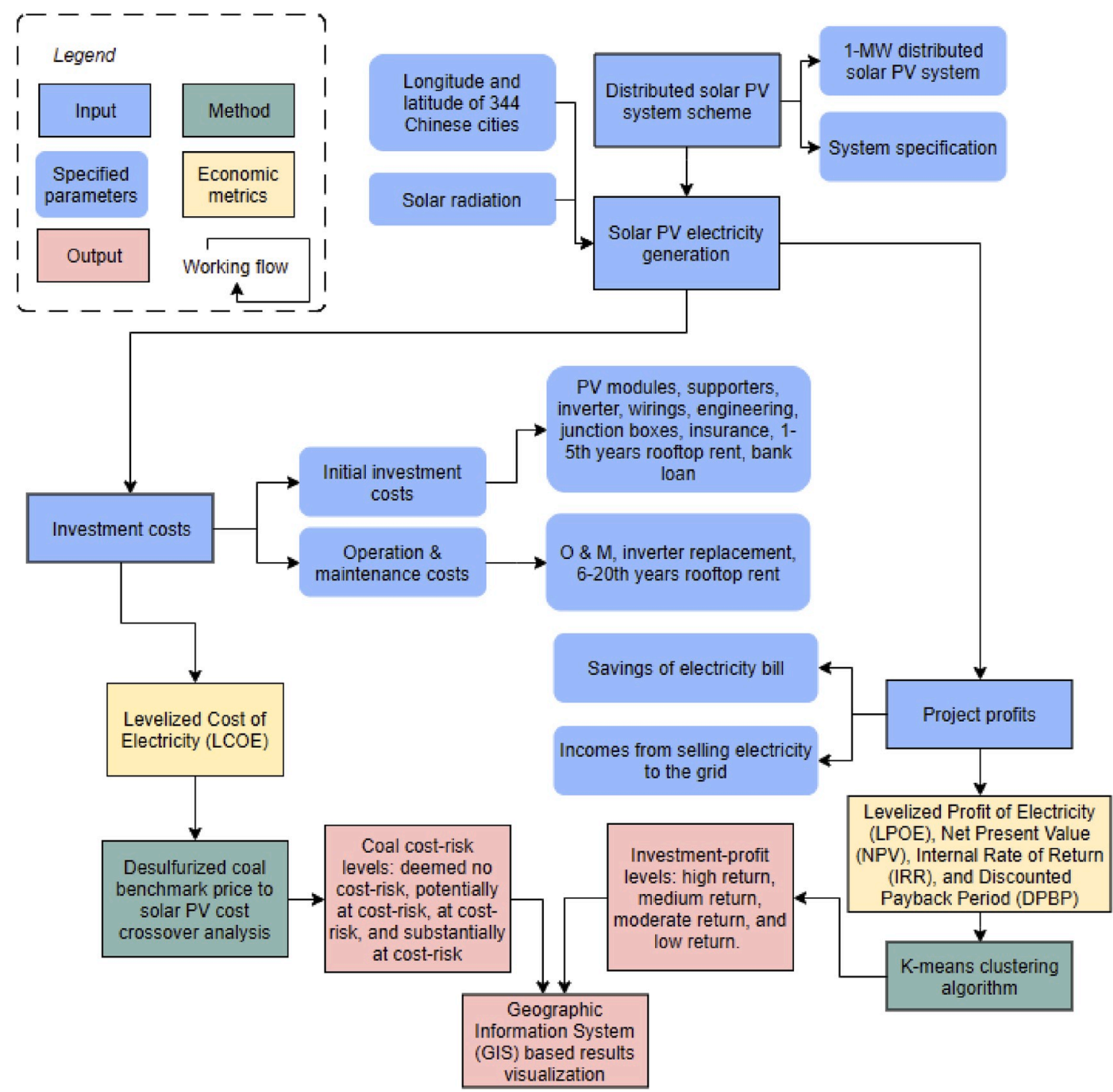

Fig. 3. The framework of the study.

assumed to be loaned from commercial banks with an $8 \%$ interest rate and 5-year payoff period [42]. The operation \& maintenance costs include 1) annual operating costs; 2) annual roof rent; 3) bank loan interest charges for the first five years. The specific values of the investment, operation, and maintenance costs are compiled from China Photovoltaic Industry Association [43] and Photovoltaic Power Systems Programme (PVPS) annual reports [44]. This paper assumes that the life cycle of the PV system is 20 years and that both the industrial and commercial electricity market price and DCB price remain the same during that 20-year lifetime. The scenario assumed in this research is based on $50 \%$ self-consumption and $50 \%$ feed-in grid.

Coal power has held a dominant position in China's electricity provision. Similar to that of the US, currently China's coal generation is also at a "cost crossover" [45]. To examine this, this study compares the DCB prices with the LCOEs of distributed solar PV projects in 344 cities. Having done so, as in the US case, this study identifies four cost-risk levels of running coal plants [46]:

Deemed no cost-risk: if DCB is $>25 \%$ lower than LCOE. Potentially at cost-risk: if DCB is $0-25 \%$ lower than LCOE. At cost-risk: if DCB is $0-25 \%$ higher than LCOE.

Substantially at cost-risk: if DCB is $>25 \%$ higher than LCOE.

These cost-risk levels can be reliable instruments to determine the cheaper option between traditional desulfurized coal generation and distributed solar PV power generation.

\subsection{Profit indicators and K-means clustering algorithm}

The investment metrics used in this paper include the classic indicators, namely, NPV, IRR, and DPBP [46]. Financial models for commercial PV investment take into account various technical and technically related assumptions in the derivation of various aspects, such as: income from PV electricity production and electricity bill savings, capital costs, and operating \& maintenance expenditures. PV financial models are used by project developers, banks, and asset managers to evaluate the profitability of a PV project. The cash flow model provides a number of parameters that allow us to rate the economic viability and profitability of a PV project.

Furthermore, the Levelized Profit of Electricity (LPOE) is identified and defined. In order to measure the net profit, this study employs LPOE as the indicator, which was introduced in our previous study [18]. This indicator is supplementary to the LCOE. It not only considers the project costs over the project's lifetime, but also the potential various incomes, namely, the savings from selling surplus electricity to the power grid, and the savings from avoiding purchasing electricity from the power grid. The LPOE formula for this paper (Equation (1)) is developed based on the LCOE formula. 


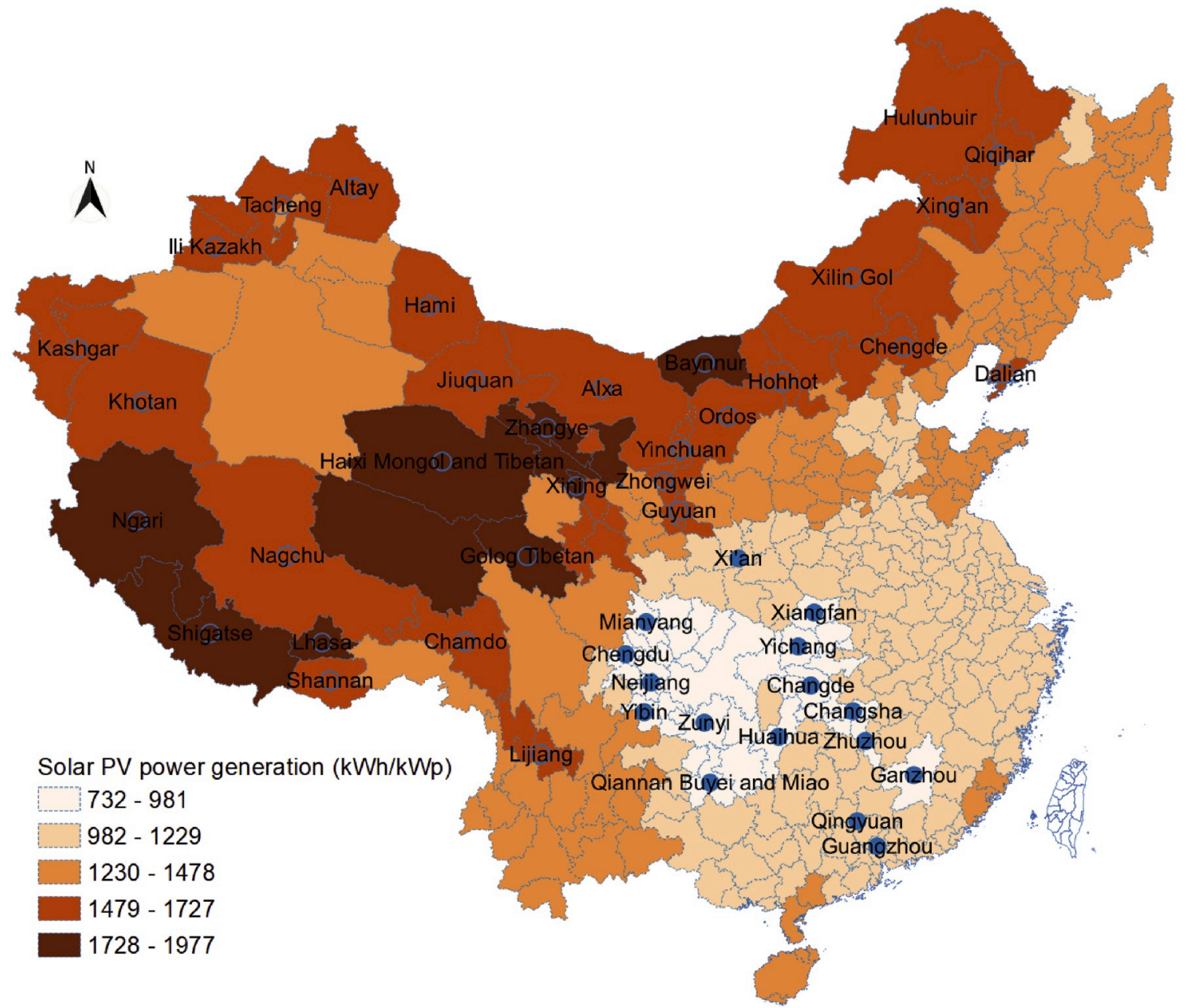

Fig. 4. The distributed solar PV system annual electricity generation $(\mathrm{kWh} / \mathrm{kWp})$. The dots represent geographical locations.

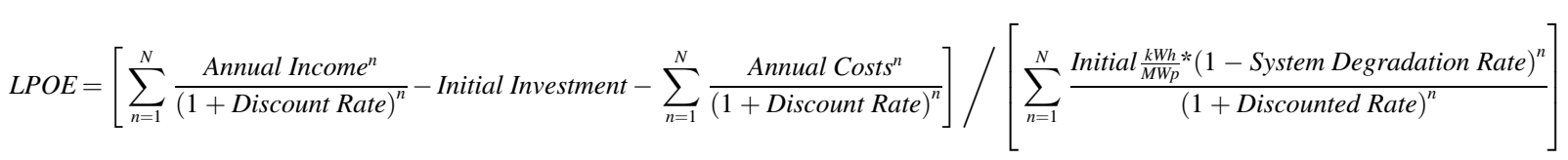

This paper is one of the few papers that bring clustering techniques into solar energy investment analysis. This paper uses the K-means clustering algorithm to divide 344 prefecture-level cities into four groups, based on the objects' intra-group similarity. Similarity in clustering analysis is defined and measured by distance functions and the number of clusters for every pair-wise combination of entities. In statistical analysis, cluster analysis can be divided into hierarchical and nonhierarchical clustering. The categorization of clustering algorithms can be described as in Fig. 5 [47]. The difference is that the data structure of the former has hierarchical classes (in a bottom-up manner or a top-down manner). The data used in this paper are cross-sectional city data, without subordination or overlapping. Therefore, it is appropriate to use the nonhierarchical clustering.

A non-hierarchical algorithm clusters the data directly into different classifications. The various methods are described in Anderberg [48]. $\mathrm{K}$-means algorithm is given the most commonly used of the partitioning

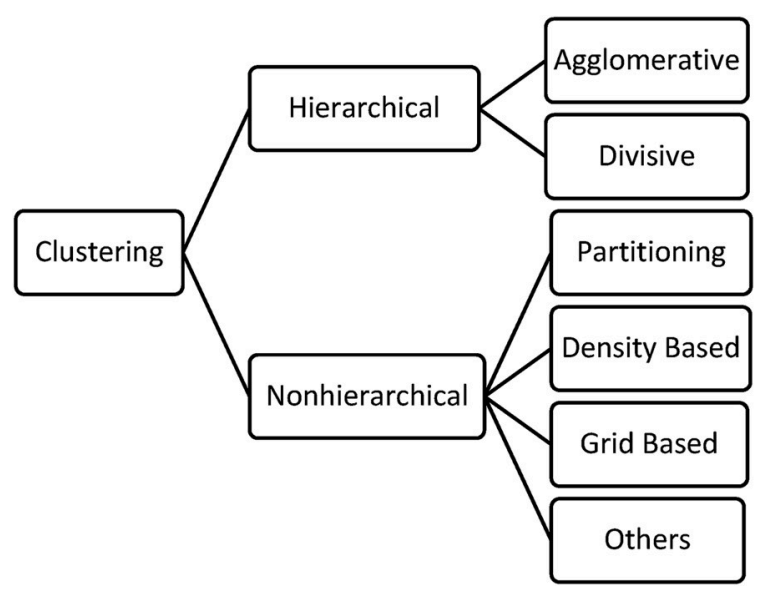

Fig. 5. Categorization of clustering algorithms. 
approach [49]. This algorithm was developed by MacQueen [50] in 1967. The main idea of K-means clustering is to choose some initial partition of data units, and then alter cluster memberships to obtain a better partition.

The clustering method used in this paper can be described in the following sequential steps:

1) A basic assumption of all clustering methods is that these numerical measures of distance are all comparable to each other [51].

2) Partition the datasets into kinitial clusters by randomly picking $k$ centers. The number of exclusively clustering number kis normally subjectively specified a priori based on interpretation. In this paper, the number is taken as four. The initial centers are picked randomly as $C_{1}^{(1)}, C_{2}^{(1)}, C_{3}^{(1)}$ and $C_{4}^{(1)}$.

3) Each item in the datasets is assigned into one specified cluster on the basis that it has the nearest distance to the assigned cluster centroid (mean). The traditional K-means clustering algorithm uses the Euclidean Distance (Equation (2) [52]) to measure similarity.

$\mathrm{d}(\mathrm{p}, \mathrm{q})=\sqrt{\sum_{i=1}^{n}\left|x_{p i}-x_{q i}\right|^{2}}$

where, $\mathrm{i}=1,2, \ldots, \mathrm{n}$.

The Euclidean Distance treats the difference between different attributes of the sample equally, which ignores the variables' dimensions. Moreover, it does not consider the correlation between variables, or the relative importance of each variable when processing data. In order to remedy these disadvantages, Mahalanobis Distance is used in this paper instead of the traditional Euclidean Distance (Equation (3)).

$\mathrm{m}(\mathrm{p}, \mathrm{q})=\sqrt{\sum_{i=1}^{n}\left(x_{p i}-x_{q i}\right)^{T} \Sigma^{-1}\left(x_{p i}-x_{q i}\right)}$

In our case, $\mathrm{p}, \mathrm{q}$ are any two points; $\mathrm{p}, \mathrm{q}=1,2, \ldots, 344$. $\mathrm{i}$ is the dimension (i.e. LPOE, NPV, IRR, and DPBP); $i=1,2,3,4$.

4) Recalculate the centroid (mean) for each cluster and decide the new

$$
\begin{array}{r}
\text { center. If } \sqrt{\sum_{i=1}^{n}\left(x_{p i}-c_{k}^{(b)}\right)^{T} \Sigma^{-1}\left(x_{p i}-c_{k}^{(b)}\right)} \\
<\sqrt{\sum_{i=1}^{n}\left(x_{p i}-c_{k}^{(a)}\right)^{T} \Sigma^{-1}\left(x_{p i}-c_{k}^{(a)}\right)}
\end{array}
$$

, then $x_{p i} \in c_{k}^{(b)}$. a and $\mathrm{b}$ are $a^{\text {th }}$ and $b^{\text {th }}$ iteration $(\mathrm{a} \neq \mathrm{b})$. $\mathrm{k}$ is the $k^{\text {th }}$ cluster, $\mathrm{k}=1,2,3,4$.

In this Step, four new centroids (mean) are generated.

5) Then Step 3) is re-conducted so that each cluster receives new items. This process is iterated until no more reassignments take place, i.e. minimizing the distance between each item and the centroids (mean).

The process can be graphically shown as Fig. 6 .

\section{Results}

This section presents the results on four levels of coal cost-risk and four city clusters of potential profits.

\subsection{Four levels of coal cost-risk}

In the US and China, the top two most important economies in the world, coal remains firmly in place as the largest $(66.54 \%$ by 2018$)$ and second-largest $(27.90 \%$ by 2018$)$ source of electricity, among other

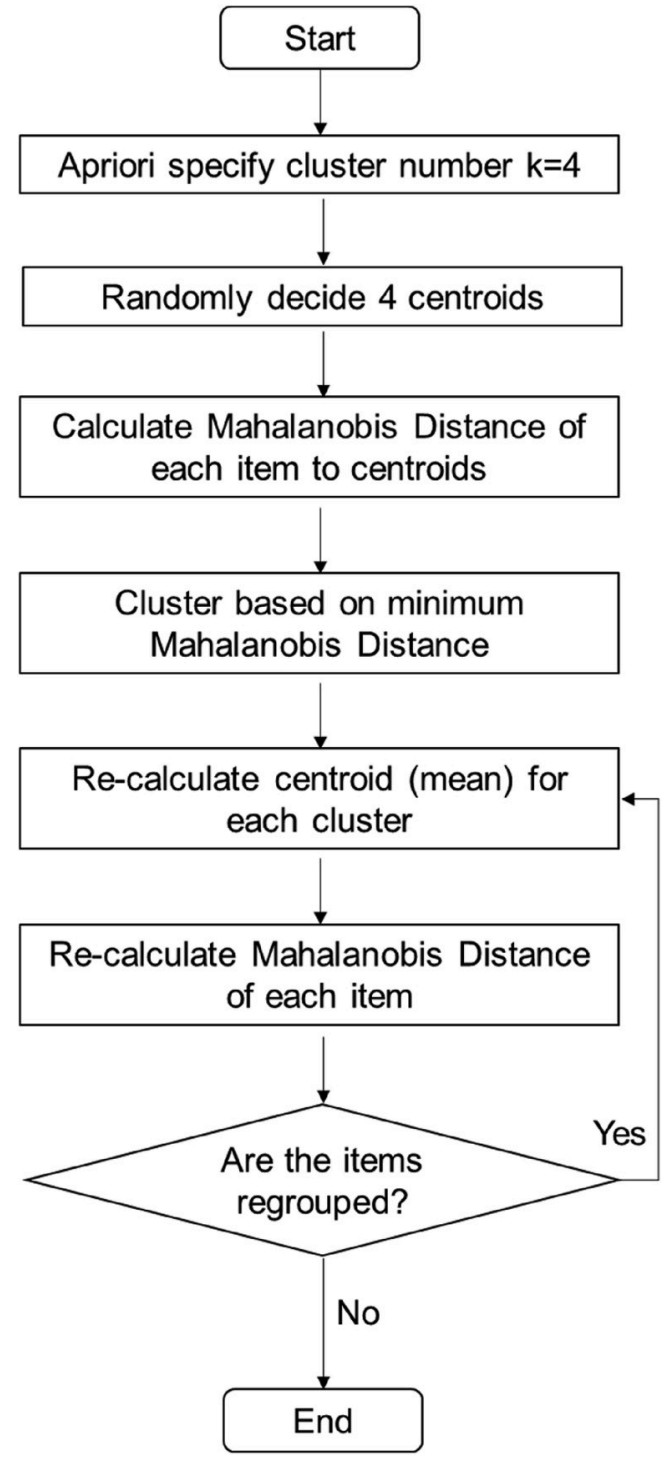

Fig. 6. K-means clustering algorithm procedure used in this paper.

energy sources [53]. Coal-fired power plants are scheduled to shut down in the coming years, with the progressive replacement by non-fossil fuels, such as solar energy. In the US, coal plant decommissions have taken place since 2010. The historical number of 13,000 MW shutting-down capacity in 2018 was the second-highest in a year, behind $19,000 \mathrm{MW}$ in 2015 [54]. One of the main reasons for these continuous retirements is the poor economics of coal plants. In China, the retreat of coal plants has not initiated yet, despite the ongoing expansion of alternative energies. In this section, a comparison of electricity costs from coal plants and solar PV projects is conducted between China and the US.

A cost-risk analysis determines the different cost-risk levels of currently running coal-fired power plants, and city magnitude, compared with the costs of distributed solar PV projects. Using the cost crossover algorithm, this paper determines that the running coal plants in 76 cities are at cost-risk from distributed solar PV projects, meaning that these running desulfurized coal-fired power plants can be replaced by distributed solar PV projects with $0-25 \%$ cheaper costs. Similarly, coal-fired power plants in 217 cities are potentially at cost-risk from distributed solar PV projects, meaning that the local DCB prices are 0-25\% lower than the distributed PV LCOE. Among these 217 cities, there is $23.04 \%$ in which the distributed solar PV LCOEs are very close to the local DCB prices (0-5\% higher than DCB prices). Lastly, the running 


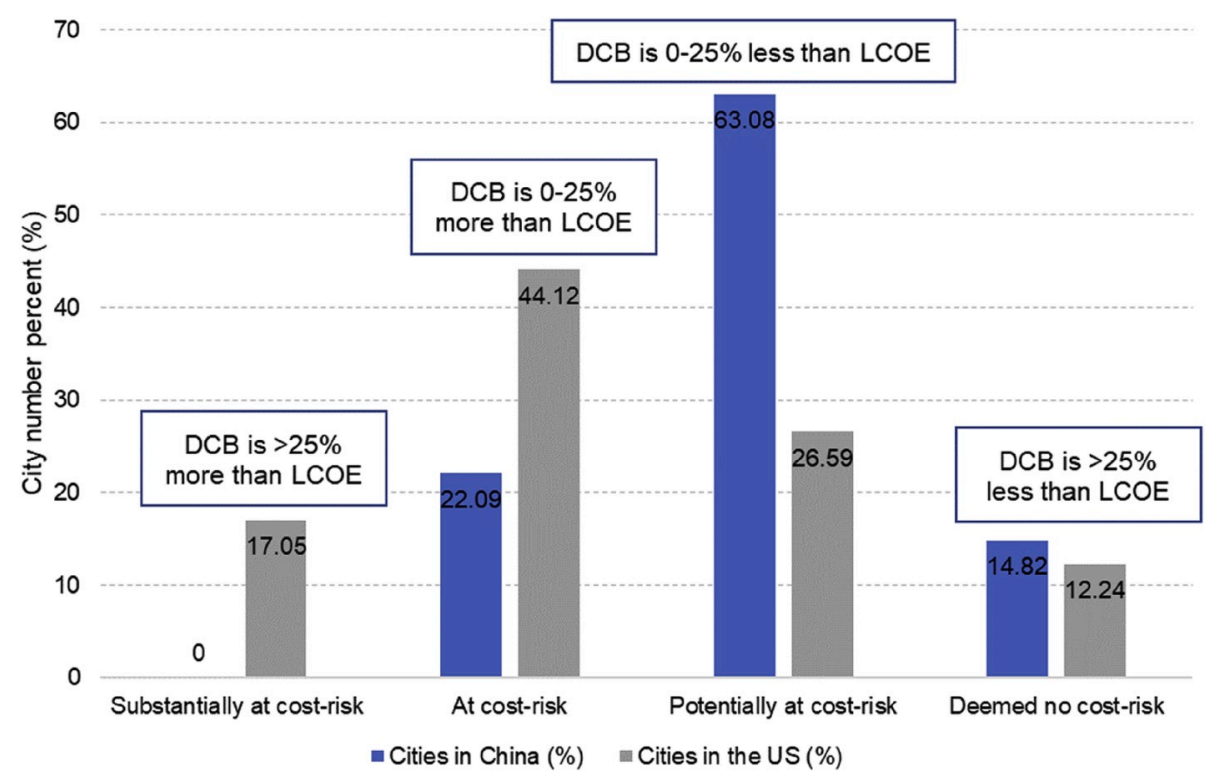

Fig. 7. Current running coal-fired power plants cost-risk levels and city number percent in China and the US [26].

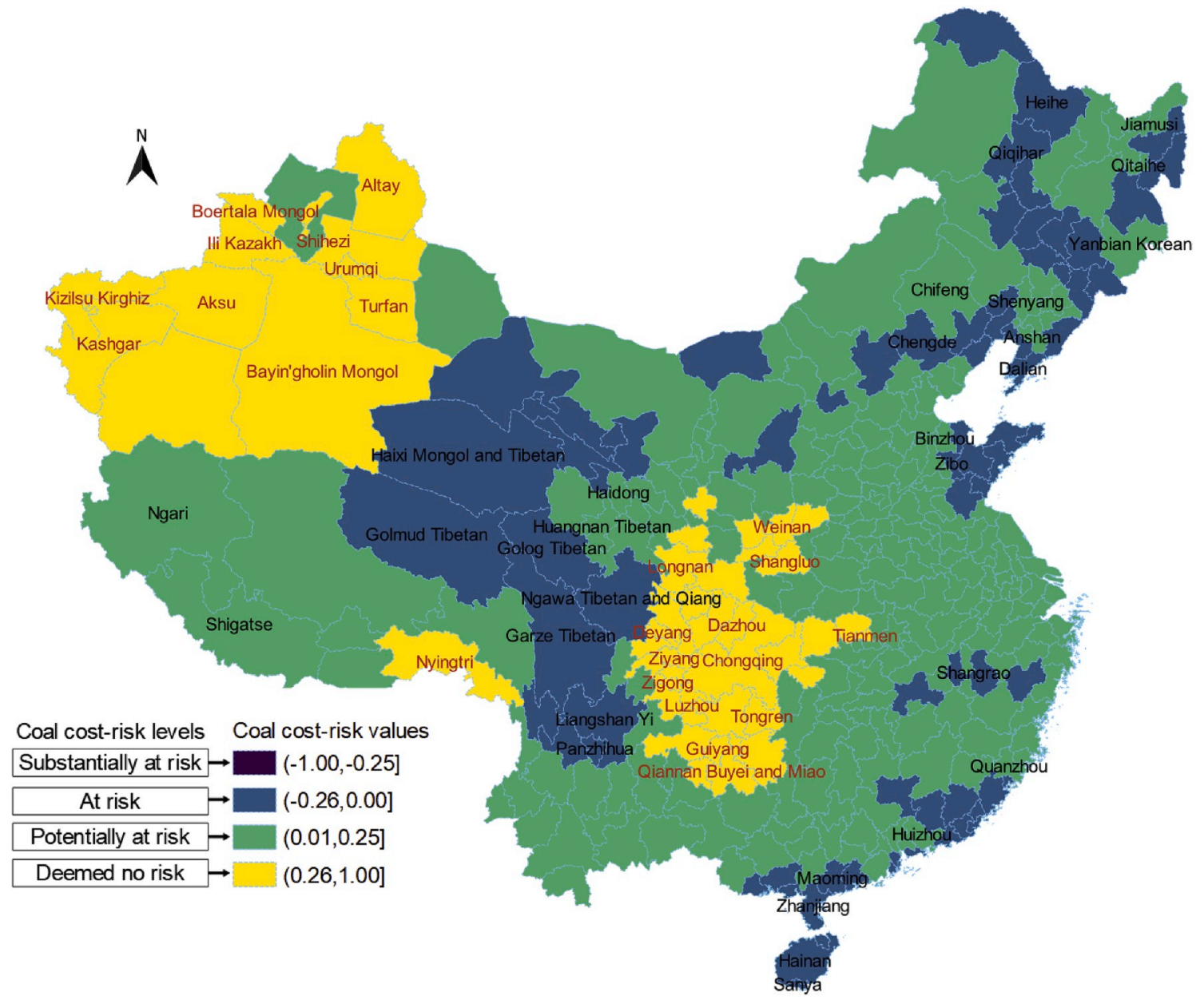

Fig. 8. The four cost-risk levels of current coal-fired power plants and their corresponding cities in China.

coal-fired power plants in 51 cities are deemed no cost-risk, meaning that the local DCB price is more than $25 \%$ less than the local solar PV LCOE. Overall, $85 \%$ of current coal-fired power plants from the investigated cities are generally under cost-risk. Furthermore, currently, local solar PV DG could replace approximately $36.63 \%$ of the Chinese coal fleet, given that the former's prices are lower than or $\leq 5 \%$ greater than the latter. Solar PV alternatives are increasingly cheaper than existing coal. The results are shown in Fig. 7. 


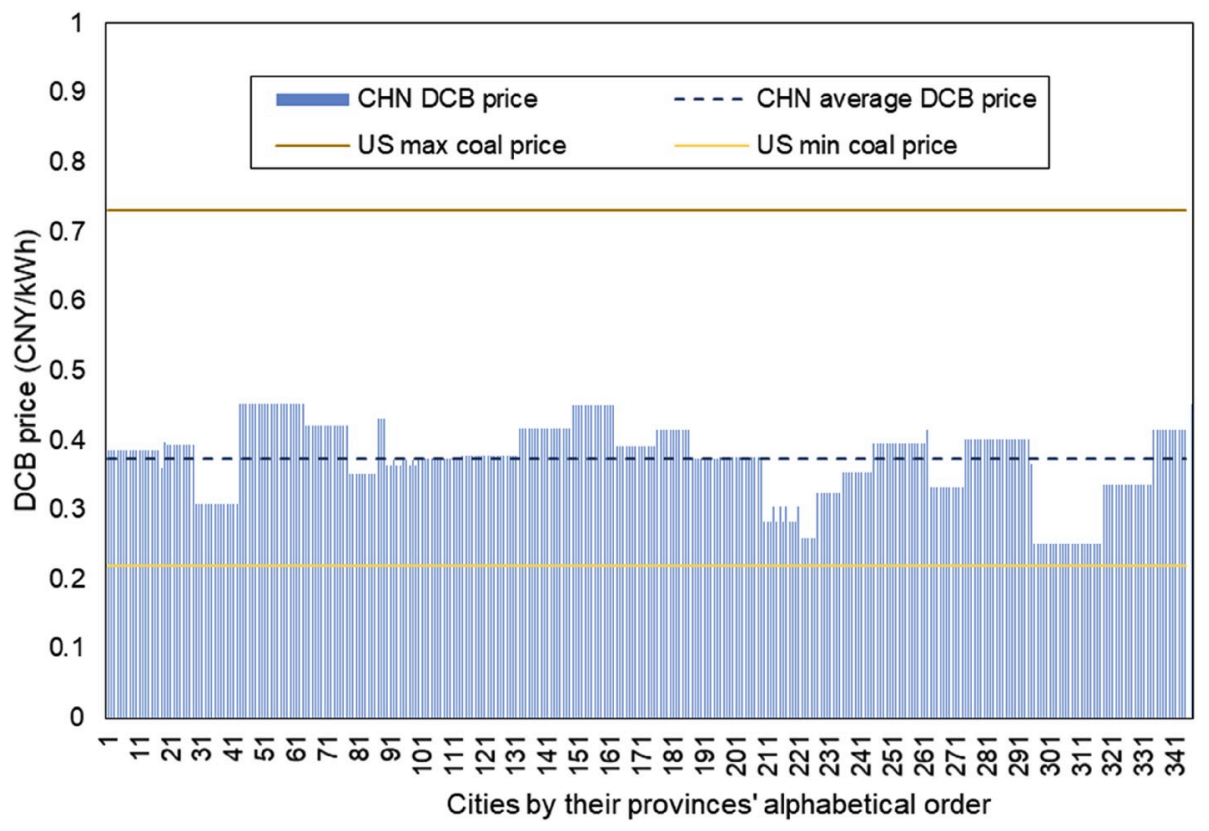

Fig. 9. The DCB prices for each city in China and the maximum and minimum marginal cost for the vast majority of coal plants in the US.

From the geographical map below (Fig. 8), the low-level cost-risk of running coal-fired power plants concentrate on the northwest area and Sichuan-basin. For most of the cities in the northeast, southeast or middle-west, the coal-fired power plants are under cost-risk.

The marginal cost of coal plants in the US is $0.22-0.73 \mathrm{CNY} / \mathrm{kWh}$ [45] (i.e. 33-111 USD/MWh, at the 2018 exchange rate from OECD [55]. Same below). In China, these costs, represented by the local DCB costs, range from 0.25 to $0.45 \mathrm{CNY} / \mathrm{kWh}$ (Fig. 9). The DCB prices in Chinese cities are mandated and regulated by the NDRC. The DCB price is calculated in each province, based on coal cost, generation cost per unit, annual power generation hours, fixed-cost of the generator, long-term loan rate, depreciation rate, proportion of self-owned funds, and repayment period. DCB prices remain controlled and flat.

The average DCB price $(0.37 \mathrm{CNY} / \mathrm{kWh})$ in China is much lower than the marginal cost of coal-fired power plants in the US [26]. Furthermore, the DCB prices are going down slightly. According to the VCE dataset, the calculated LCOEs in the US are between 0.19 and $0.34 \mathrm{CNY} / \mathrm{kWh}$ (i. e. 28-52 USD/MWh); meanwhile, in China, the calculated LCOEs in this study are between 0.25 and $0.68 \mathrm{CNY} / \mathrm{kWh}$ (Fig. 10). Therefore, with the lower marginal costs of coal-fired power plants and the higher LCOEs of distributed solar PV, coal-fired power plants in China are much "safer" than those in the US, a fact that also imposes pressure on solar power costs in China.

Nevertheless, 126 cities in China have already achieved almost the same or even lower LCOEs from distributed solar projects relative to their local DCB prices, which implies the potential replacement of coalfired power plants by distributed solar power generation without FITs. The LCOE of distributed solar power continues to drop rapidly, effectively making it commercially competitive with coal power in China.

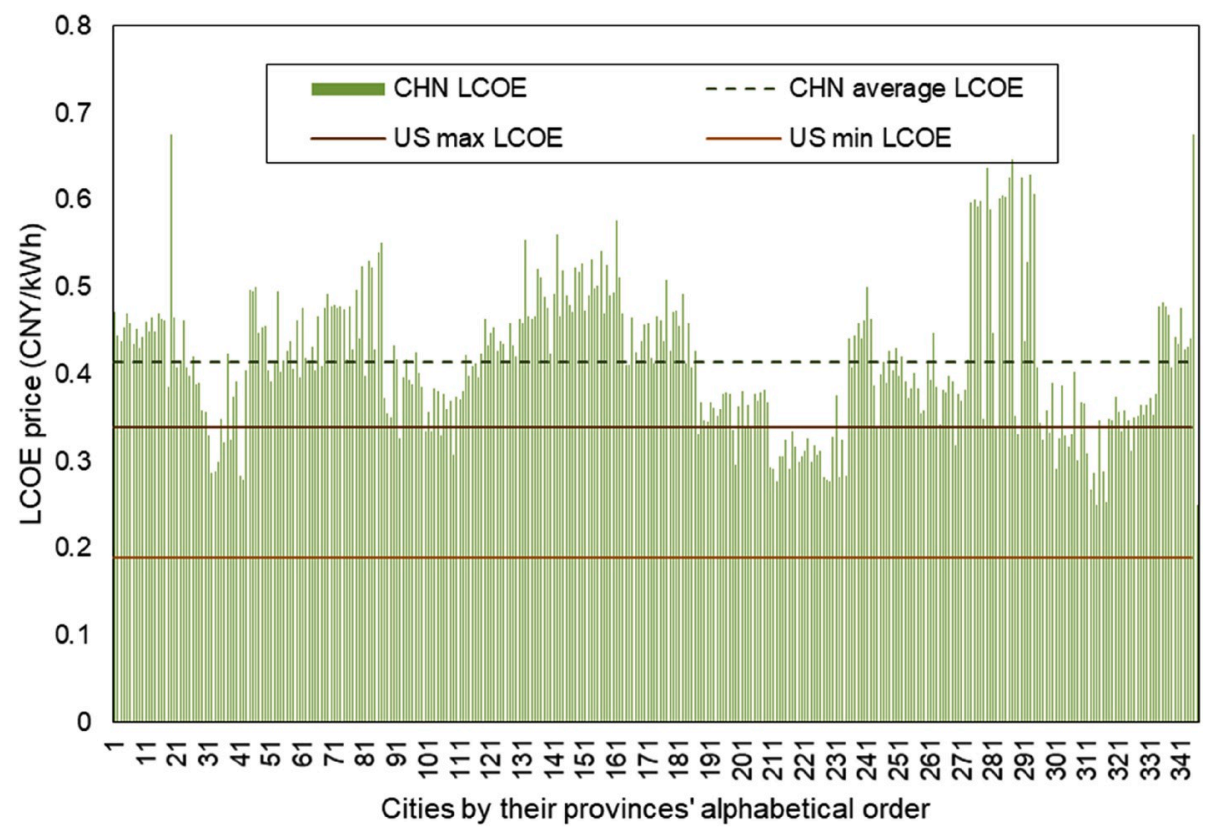

Fig. 10. The calculated LCOEs for each city in China and the maximum and minimum LCOEs in the US from the VCE dataset. 
Table 1

The city numbers for each city cluster.

\begin{tabular}{lllll}
\hline $\begin{array}{l}\text { Parameter (LPOE, } \\
\text { IRR, DPBP, NPV) }\end{array}$ & $\begin{array}{l}\text { Cluster 1: } \\
\text { high return }\end{array}$ & $\begin{array}{l}\text { Cluster 2: } \\
\text { medium } \\
\text { return }\end{array}$ & $\begin{array}{l}\text { Cluster 3: } \\
\text { moderate } \\
\text { return }\end{array}$ & $\begin{array}{l}\text { Cluster 4: } \\
\text { low return }\end{array}$ \\
\hline City numbers & 1 & 74 & 152 & 117 \\
\hline
\end{tabular}

Table 2

ANOVA table for $\mathrm{F}$ tests results.

\begin{tabular}{lllllllll}
\hline \multirow{2}{*}{ Parameter } & \multicolumn{2}{l}{ Cluster } & & & Error & \multirow{2}{*}{ F } & \multirow{2}{*}{ Sig. } \\
\cline { 2 - 3 } & Mean Square & $\mathrm{df}$ & & Mean Square & Df & & \\
\hline LPOE & $8.796 \mathrm{E}+11$ & 3 & & $1.099 \mathrm{E}+9$ & 340 & 800.653 & .000 \\
IRR & $8.212 \mathrm{E}+11$ & 3 & & $1.026 \mathrm{E}+9$ & 340 & 800.195 & .000 \\
DPBP & $1.582 \mathrm{E}+15$ & 3 & & $1.993 \mathrm{E}+12$ & 340 & 793.896 & .000 \\
NPV & $2.361 \mathrm{E}+26$ & 3 & & $2.953 \mathrm{E}+23$ & 340 & 799.627 & .000 \\
\hline
\end{tabular}

\subsection{Four city clusters of potential profits}

Section 3.1 emphasizes the potential of replacing coal-fired power plants with distributed solar PV. This section explores the current investment returns on distributed solar PV in different cities, and the factors affecting these investment returns.

After running the K-means clustering algorithm in SPSS ${ }^{\circledR}$ software, all the 344 prefectural-level cities are categorized into four clusters, based on the Mahalanobis Distance. The city numbers for each city cluster are shown in the following Table 1.

The calculation results are tested by the F test. The following Analysis of Variance (ANOVA) in Table 2 shows the robust results of $F$ tests. The significance test in ANOVA evaluates the between-group variability against the within-group variability.

The clustering results can be shown in Fig. 11 below. City cluster 1 has the superiority of investment-profits over the other three city clusters.

Cities in clusters 1 and 2-concentrated in the northwest and northeast areas-feature large landmass, abundant solar resources, and relatively sparse population. In these areas, the solar energy curtailment of large-scale solar power production is one significant problem. In 2017, the curtailment rates in Xinjiang and Gansu were $21.6 \%$ and $20.8 \%$, which accounted for $70 \%$ of the curtailment in the northwest of China [56]. However, distributed solar PV power generation can be a better solution. Investing in city clusters 1 and 2 has the advantages of: higher level of solar resources, and competitive market prices (Fig. 12 a d). Solar radiation, electricity market price, and self-consumption ratio are the most sensitive variables concerning the project benefits (represented by LPOE), according to Monte Carlo sensitivity analysis [18]. The yearly solar power generation of cluster 1 and 2 varies from 1280 to $1976 \mathrm{kWh} / \mathrm{kWp}$, with an average of $1509 \mathrm{kWh} / \mathrm{kWp}$. The market prices can be as high as $1.8 \mathrm{CNY} / \mathrm{kWh}$, and the average price is $0.74 \mathrm{CNY} / \mathrm{kWh}$. Strong solar radiation and electricity market price make it possible to yield high investment returns. Nevertheless, strong power grid infrastructures for supporting cross-province transmission are expected, due to the relatively low electricity demands.

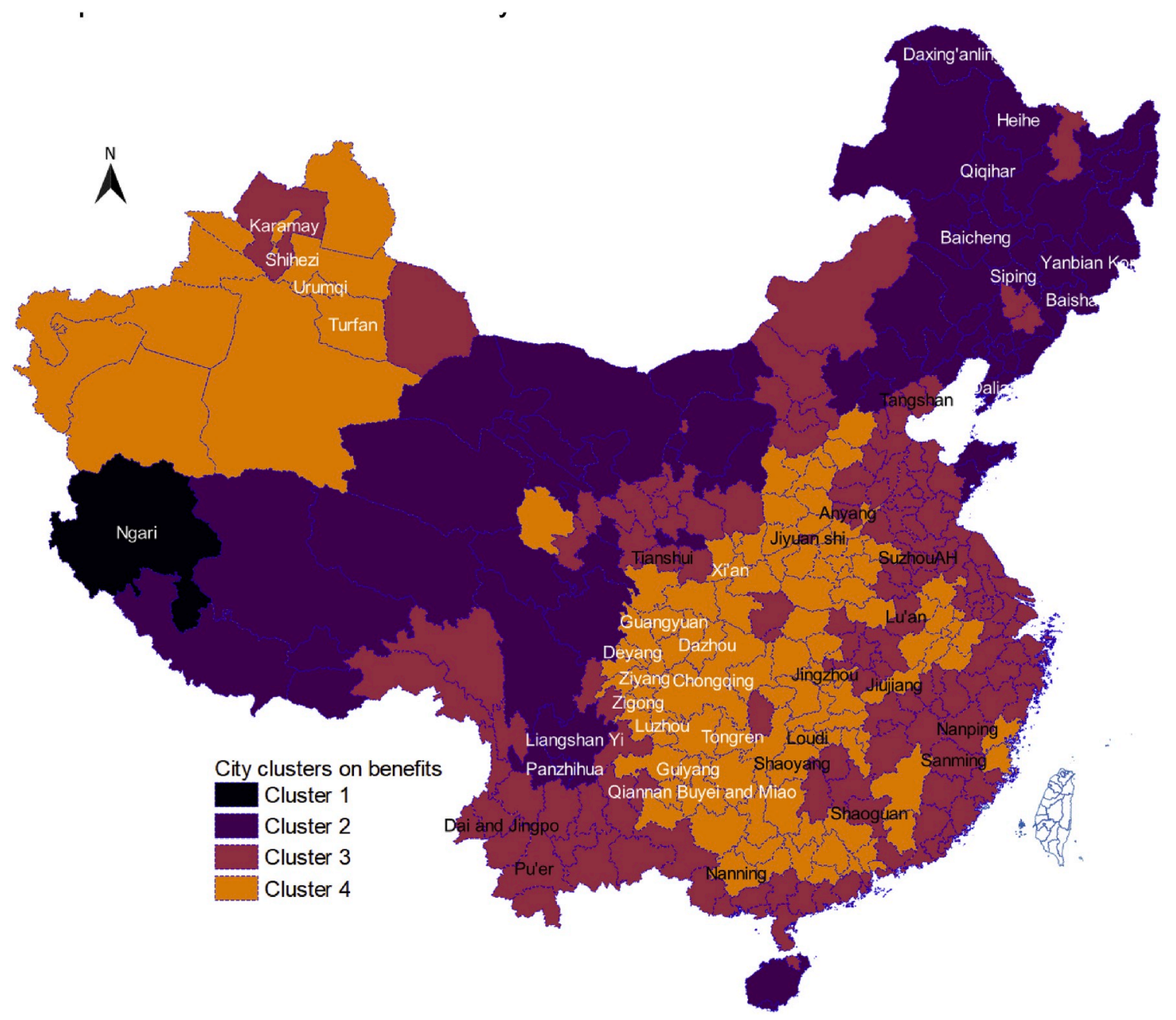

Fig. 11. Four city clusters of distributed solar PV investment-profits. 


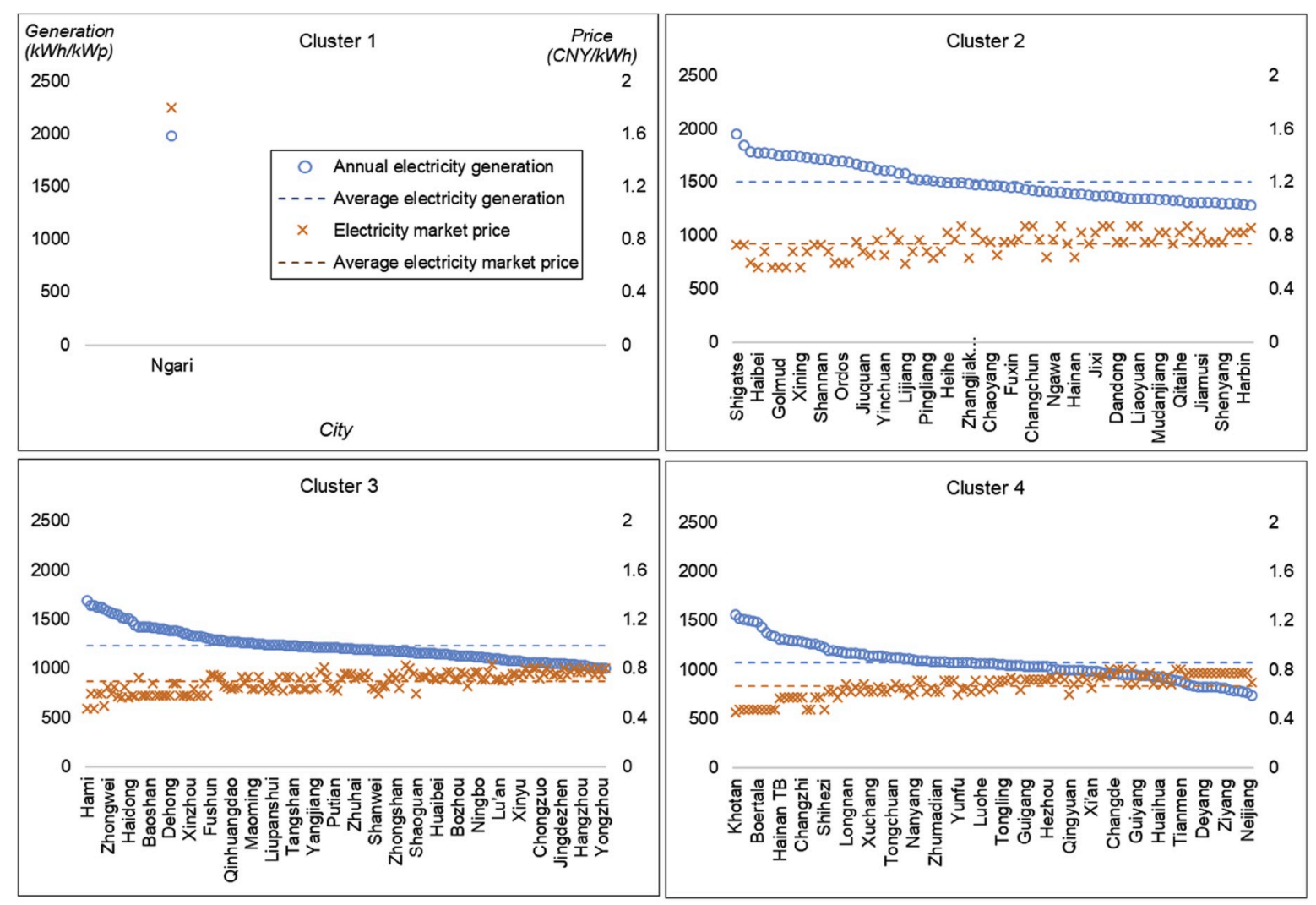

Fig. 12. a-d. The electricity generation from solar PV and the electricity market price in each cluster. For each panel, the primary $Y$-axis represents the electricity generation in $\mathrm{kWh} / \mathrm{kW}_{\mathrm{p}}$, and the secondary $\mathrm{Y}$-axis represents the electricity market price in $\mathrm{CNY} / \mathrm{kWh}$. The X-axis represents the cities (descending order of annual electricity generation).

Investing in city cluster 3 -which contains cities scattered through the southeast, southwest, and part of the northern area-has the advantage of higher electricity demands. Many manufacturing enterprises are regionally clustered in these areas, especially in the eastern coastal cities with good market access [57]. Investing in distributed solar PV applications will benefit from high electricity demand and abundant rooftop area, to achieve scale economics. However, a well-designed and market-oriented trading system for solar power is necessary for the cities in cluster 3 . Specifically, this refers to the electricity prices design concerning differences between load matching and grid importation/exportation. This requires the deregulation of the electricity retail market, and the development of inter-regional electricity trading, which will change the interactions between power grid companies, generators, and end-users [58].

Investing in city cluster 4 has fewer advantages relative to the other three city clusters. Still, investments can be made on poverty-alleviation projects and public-use projects, e.g. applications in urban lighting and traffic signals. The poverty-alleviation PV program initiated in 2014 has an ambitious aim of adding over $10 \mathrm{GWp}$ and benefiting more than 2 million households by 2020 [58]. Qinghai, Sichuan, Yunnan, and Shaanxi provinces are among the main provinces, and have various preferential policies, e.g. credit support from China Development Bank, and special funds from local governments [59].

\section{Discussions}

The results imply that the current distributed solar power costs have decreased to the point that they are now at or below the marginal cost of conventional generation. To gradually transform the coal-fired power systems to solar, flexibility problems caused by integrating higher shares of solar power are not neglectable. Firstly, this section discusses how different self-consumption rate, as one of the sensitive factors in this study, could affect the profitability and indirectly improve the flexibility. Secondly, this section discusses the "additional cost" by flexibility issues and countermeasures.

\section{2. "Additional cost"}

On the one hand, the reduction of solar PV costs provides cheaper and cleaner electricity to end-users. Local regulators and utilities should consider a smooth shut-down of old coal-fired power plants. On the other hand, a higher share of solar energy and other renewable sources raises substantial flexibility issues for the electricity system, due to the variability, uncertainty, and non-synchrony of solar power generation [63]. Specifically, solar power generation varies as the weather fluctuates or clouds pass over, which leads to inaccurate supply predictions [62]. "Over-generation" and "under-generation" may occur spontaneously, leading to the curtailment and fast adjustment of power. "Additional cost" is generated in order to maintain the balance between electric supply and demand. The penetration of solar PV power also adds challenges to power grid system frequency. Hence, another "additional cost" is needed to maintain power system stability. These "additional costs" increase as solar power penetration increases [64]. When solar PV power increases to about $15 \%$ (measured in $\mathrm{kWh}$ of generated electricity), the solar PV average wholesale price would drop $45 \%-55 \%$ per $\mathrm{kWh}$, relative to zero penetration. When penetration increases to $30 \%$, the price reduction can be around 70\% [65]. According to research by UKERC [66], a total cost of 15-45 GBP/MWh (132-397 CNY/MWh [55]) will be added for reserve requirements when renewable energy reaches 50\% penetration; and a 5-20 GBP/MWh (44-176 CNY/MWh) additional cost will be added for upgrading the electricity transmission network. With the decreasing prices of solar PV systems, less money is spent on energy, but more money is spent on these "services."

As it has been pointed out in this paper, $85.17 \%$ of the currently 
running coal-fired power plants are under cost-risk because of solar PV applications. Investing in city clusters 1, 2, and 3-which accounts for $65.99 \%$ of Chinese cities-will enable a higher than $8 \%$ IRR, and a maximum of 15 years DPBP. However, this only means that investments are profitable for individual investors; it does not indicate that solar power is profitable on a societal level. The full energy value of solar technologies can only be understood in the context of the generation system as a whole, considering the flexibility challenges addressed above.

In such a situation, both technical options and managerial options should be considered to mitigate these challenges. First, increasing the self-consumption rate to directly offset demand is recommended. Currently, a higher self-consumption rate not only provides a cheaper electricity resource, but also implies a stable electricity supply. The use of battery storage and/or power-to-heat (thermal storage) solutions can favor the increase of self-consumption [62]. Second, from a policy perspective, a well-designed incentive scheme could increase self-consumption, decrease the use of transmission lines, and increase the independence of customers from central grid power. China is taking steps towards peer-to-peer trading of Distributed Generation [67]. Three business modes among Distributed Generators, end-users, and local power grid companies were proposed for the pilot: direct sales, entrust sales, and sales to the grid. This is expected to redefine DG business models and bring new opportunities for DG investment to serve industrial and commercial customers. A new role-the aggregator, who will integrate customers' electricity consumption behavior and power grid services-is expected to appear in an established market [68]. One single aggregator can offer limited services to customers and the grid. But a relatively large number of aggregators can create a single, large and predictable entity, and provide new services to the system for a longer duration. However, due to complexity, this policy only gave an overview of new thinking, with many details left to be decided. For instance, grid-coordination ability for interprovincial and interregional trading, and the compensation mechanism for distributed resources.

\subsection{Self-consumption rate}

Sensitivity analysis suggests that analyzing different selfconsumption rates would be helpful to understand how these rates affect various economic parameters. The decentralized nature of solar PV technology allows producers to consume generated power directly on site. In this paper, the self-consumption rate is defined as the ratio of direct consumption of solar PV power by end-users to total solar PV power generation [60]. This is an attractive proposition for commercial energy consumers in particular, when the costs of solar power generation are below the costs of purchased electricity. The self-consumption share varies widely from customer to customer. From previous results [18], the costs of solar power generation are lower than the costs of purchased electricity from the power grid in all cities. In China, self-consumption is more economically viable than buying electricity from the power grid. As a forecast, the continuous declining costs of solar PV power generation will give more economic incentives to self-consumption than to buying electricity from the power grid.

Increasing self-consumption could also raise the profits of solar PV systems. In this paper, a $50 \%$ self-consumption rate is assumed. Since electricity market prices are higher than DCB prices in all cities in China, an increased self-consumption rate implies more financial savings, which can be perceived as potential benefits. From the five different selfconsumption scenarios below (Fig. 13), a higher self-consumption rate shows a better financial performance. In fact, the studies in many cases reveal that self-consumption is economically viable, although different regulatory policies may impact its profitability [61]. Self-consumption provides some level of independence against unstable power grids and electricity market price inflation. It also lowers the stress on the electricity distribution grid, by offsetting demand on the generation side [62].
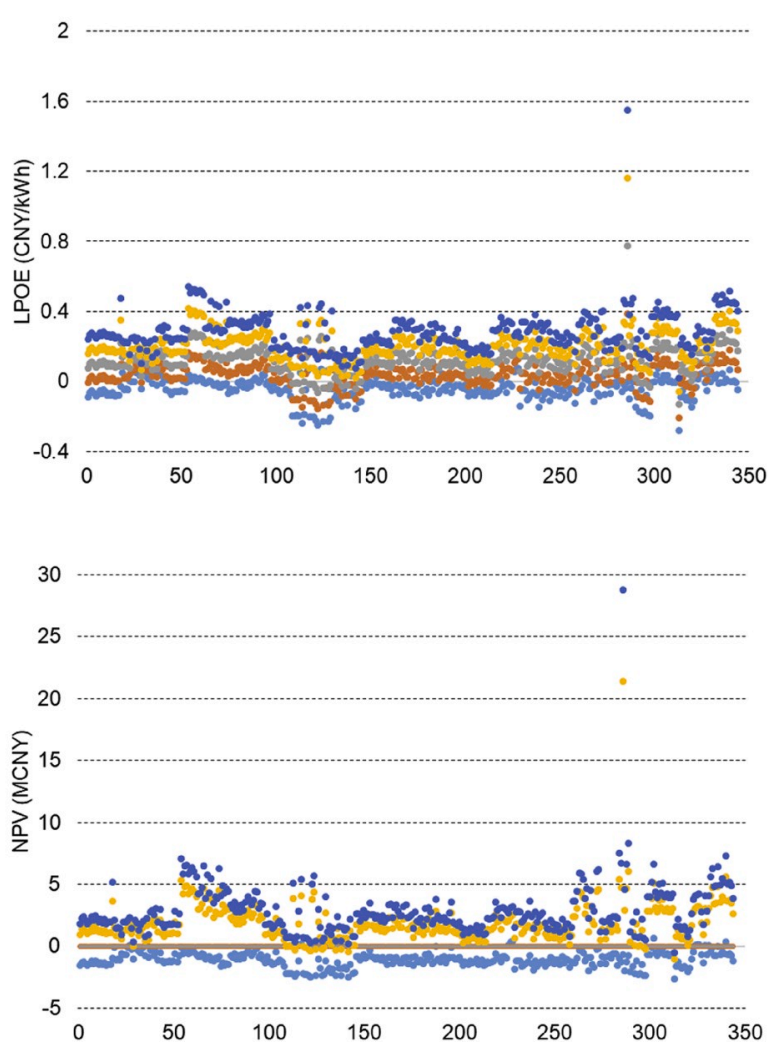

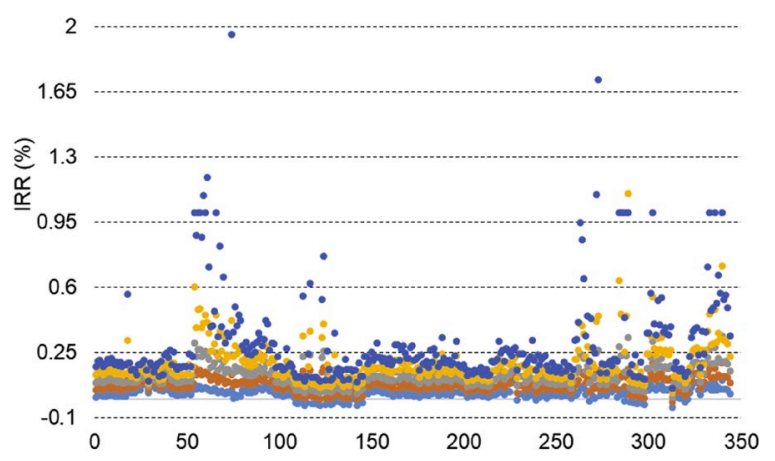

Fig. 13. Different self-consumption rates (SCR) of $0 \%, 25 \%, 50 \%, 75 \%$ and $100 \%$ impact economic performances. 


\section{Conclusions}

Coal generation is at a crossroads in China, or more precisely at a "cost crossover". Due to the recent rapid cost decline of solar, the combined fuel, maintenance, and other going-forward costs of coal-fired power in many existing coal plants are now more expensive than the allin costs of new solar projects. This study uses the cost crossover approach to measure the replacement of current running coal plants by distributed solar PV projects, and identify all the coal plants into four cost-risk levels. Based on replacement potential, this study also examines the different profit levels of investment in solar PV projects. Both the results of cost-risk and the investment returns are mapped based on GIS. Conclusions can be drawn as follows.

The results suggest $85.17 \%$ of the currently running coal-fired power plants are under cost-risk, given comparisons to the LCOEs of distributed solar PV projects. This reveals that most distributed solar PV projects across different Chinese cities can achieve a levelized cost that is competitive enough with current published DCB prices. Approximately $36.63 \%$ of current Chinese coal-fired power plants can be replaced by distributed solar PV projects.

From the investment-profit examination, $21.80 \%$ of all the investigated cities have a medium or high return. $44.19 \%$ of cities can generate moderate returns. Investing in city clusters 1, 2, and 3, which have been identified in this study, will enable a higher than $8 \%$ IRR, and a maximum of 15 years DPBP. Investing in distributed solar PV facilities in these cities can benefit from: abundant solar resources, competitive electricity market prices, high electricity demand, and copious rooftop area. Meanwhile, investing in city cluster 4 will fail to guarantee capital recovery during a solar PV project's lifetime. However, investing in poverty-alleviation projects can become beneficial, with preferential support from local governments.

Different self-consumption rates will impact profitability. In China, the LCOEs of distributed solar PV projects have achieved a level at which they are excessively competitive with the electricity purchased price. Hence, a higher self-consumption rate implies more financial savings. Batteries and/or thermal storage can be a technical solution. A wellestablished market mechanism for electricity trading could fully exploit the economic potential of PV self-consumption. DG on the demand side is encouraged to operate as the generation with selfconsumption and the redundant energy fed into the grid, so as to realize the optimum allocation of distributed resources.

"Additional costs" due to DG penetration should be accounted for, considering, for instance, the costs of fast adjustment of power, the costs of system reserves to meet short-term balancing requirements, and the costs of transmission and distribution network reinforcement. In this sense, the lower LCOEs of current distributed solar PV applications could not be perceived simply as absolute economic advantages. More studies should follow up on how to maximize the use of variable renewable generation, whilst minimizing "additional costs" by increasing system flexibility.

This paper provides a useful attempt on the transition to loweremitting and more flexible electricity systems while delivering economic benefits to consumers and investors. The novelty of this research is the establishment of substitution possibility from an economic perspective and the estimation of investment profitability in all cities in China, which is unique (to authors' knowledge). In the future, the work could be enhanced by performing a more complete and robust analysis by combining technical, economic, and social factors. It is also worthy of discussing more market designs in order to safeguard the integration of renewables without harassing the economic viability and system flexibility in current power generation units.

\section{Data availability}

The data that support the plots within this paper and other findings of this study are available from the corresponding authors upon request.

\section{Declaration of competing interest}

The authors declare that there are no financial or non-financial competing interests.

\section{CRediT authorship contribution statement}

Ying Yang: Conceptualization, Methodology, Software, Data curation, Visualization, Writing - original draft, Writing - review \& editing. Pietro Elia Campana: Software, Validation, Writing - review \& editing. Jinyue Yan: Supervision, Writing - review \& editing, Funding acquisition, Project administration.

\section{Acknowledgements}

This work has received funding from KKS Future Energy Profile through the projects iREST and FREE. This study has also received funding from the European Community's H2020 Framework Programme under grant agreements No 646529 and 774309. The authors would like to give thanks for support from the National Key Research and Development Program of China (Grant No. 2016YFE0102400). Ying Yang acknowledges the financial support from the China Scholarship Council (CSC).

\section{References}

[1] Bi G, Shao Y, Song W, Yang F, Luo Y. A performance evaluation of China's coalfired power generation with pollutant mitigation options. J Clean Prod 2018;171: 867-76.

[2] Wu XD, Yang Q, Chen GQ, Hayat T, Alsaedi A. Progress and prospect of CCS in China: using learning curve to assess the cost-viability of a $2 \times 600 \mathrm{MW}$ retrofitted oxyfuel power plant as a case study. Renew Sustain Energy Rev 2016. https://doi. org/10.1016/j.rser.2016.03.015.

[3] Zhang X, Liu J, Tang Y, Zhao X, Yang H, Gerbens-Leenes PW, et al. China's coalfired power plants impose pressure on water resources. J Clean Prod 2017. https:// doi.org/10.1016/j.jclepro.2017.04.040.

[4] Duan HB, Zhang GP, Zhu L, Fan Y, Wang SY. How will diffusion of PV solar contribute to China's emissions-peaking and climate responses? Renew Sustain Energy Rev 2016. https://doi.org/10.1016/j.rser.2015.09.021.

[5] Liu Q, Lei Q, Xu H, Yuan J. China's energy revolution strategy into 2030. Resour Conserv Recycl 2018. https://doi.org/10.1016/j.resconrec.2017.09.028.

[6] National Development, Reform Commission. Notice on exerting price leverage to promote the healthy development of the solar PV industry 2013. accessed, http ://www.gov.cn/jrzg/2013-08/31/content_2478170.htm. [Accessed 2 April 2020].

[7] National Energy Administration. Notice on further implementing relevant policies on distributed solar PV power generation. 2014. accessed, http://zfxxgk.nea.gov. cn/auto87/201409/t20140904_1837.htm. [Accessed 2 April 2020].

[8] Zhang S, He Y. Analysis on the development and policy of solar PV power in China. Renew Sustain Energy Rev 2013;21:393-401. https://doi.org/10.1016/j. rser.2013.01.002.

[9] Zhang F, Deng H, Margolis R, Su J. Analysis of distributed-generation photovoltaic deployment, installation time and cost, market barriers, and policies in China. Energy Pol 2015;81:43-55. https://doi.org/10.1016/j.enpol.2015.02.010.

[10] Yuan C, Liu S, Yang Y, Chen D, Fang Z, Shui L. An analysis on investment policy effect of China's photovoltaic industry based on feedback model. Appl Energy 2014;135:423-8. https://doi.org/10.1016/j.apenergy.2014.08.103.

[11] National Energy Administration. Photovoltaic power generation statistics for 2018 2019. accessed, http://www.nea.gov.cn/2019-03/19/c_137907428.htm. [Accessed 2 April 2020].

[12] Green MA, Hishikawa Y, Dunlop ED, Levi DH, Hohl-Ebinger J, Ho-Baillie AWY. Solar cell efficiency tables (version 1-52). Prog Photovoltaics Res Appl 2018;26: 427-36. https://doi.org/10.1002/pip.3040.

[13] Wang S. China's photovoltaic market is transforming 2019. accessed, http://ex.bjx. com.cn/html/20190102/29465.shtml. [Accessed 2 April 2020].

[14] Zou H, Du H, Ren J, Sovacool BK, Zhang Y, Mao G. Market dynamics, innovation, and transition in China's solar photovoltaic (PV) industry: a critical review. Renew Sustain Energy Rev 2017;69:197-206. https://doi.org/10.1016/j. rser.2016.11.053.

[15] Zhao X, Zeng Y, Zhao D. Distributed solar photovoltaics in China: policies and economic performance. Energy 2015;88:572-83. https://doi.org/10.1016/j. energy.2015.05.084.

[16] National Development, Reform Commission of China; Ministry of Finance; National Energy Agency. Notice on matters relevant to PV power generation in 2018. 2018. accessed, https://www.ndrc.gov.cn/xxgk/zcfb/tz/201806/t201806 01_962736.html. [Accessed 2 April 2020].

[17] National Development, Reform Commission, National Energy Administration. Notice on actively promoting the work of wind and photovoltaic power generation 
with no subsidies and fair price access to the grid. 2019. accessed, http://www. nea.gov.cn/2019-01/10/c_137731320.htm. [Accessed 2 April 2020].

[18] Yan J, Yang Y, Elia Campana P, He J. City-level analysis of subsidy-free solar photovoltaic electricity price, profits and grid parity in China. Nat Energy 2019;4 709-17. https://doi.org/10.1038/s41560-019-0441-z.

[19] China brings solar home. Nat Energy 2019;4:623. https://doi.org/10.1038/ s41560-019-0458-3.

[20] Figueiredo R, Nunes P, Meireles M, Madaleno M, Brito MC. Replacing coal-fired power plants by photovoltaics in the Portuguese electricity system. J Clean Prod 2019. https://doi.org/10.1016/j.jclepro.2019.02.217.

[21] Leonard MD, Michaelides EE, Michaelides DN. Substitution of coal power plants with renewable energy sources - shift of the power demand and energy storage. Energy Convers Manag 2018. https://doi.org/10.1016/j.enconman.2018.02.083.

[22] Chapman AJ, McLellan BC, Tezuka T. Prioritizing mitigation efforts considering cobenefits, equity and energy justice: fossil fuel to renewable energy transition pathways. Appl Energy 2018. https://doi.org/10.1016/j.apenergy.2018.03.054.

[23] Lee CY, Lee MK, Yoo SH. Willingness to pay for replacing traditional energies with renewable energy in South Korea. Energy 2017. https://doi.org/10.1016/j. energy.2017.04.037.

[24] Prehoda EW, Pearce JM. Potential lives saved by replacing coal with solar photovoltaic electricity production in the U.S. Renew Sustain Energy Rev 2017. https://doi.org/10.1016/j.rser.2017.05.119.

[25] Ming Z, Ximei L, Yulong L, Lilin P. Review of renewable energy investment and financing in China: status, mode, issues and countermeasures. Renew Sustain Energy Rev 2014;31:23-37. https://doi.org/10.1016/j.rser.2013.11.026.

[26] Wei H, Liu J, Yang B. Cost-benefit comparison between domestic solar water heater (DSHW) and building integrated photovoltaic (BIPV) systems for households in urban China. Appl Energy 2014. https://doi.org/10.1016/j.apenergy.2014.04.003.

[27] Wang Y, Zhou S, Huo H. Cost and $\mathrm{CO} 2$ reductions of solar photovoltaic power generation in China: perspectives for 2020. Renew Sustain Energy Rev 2014. https://doi.org/10.1016/j.rser.2014.07.027.

[28] Reddy TA. Applied data analysis and modeling for energy engineers and scientists. Springer Science \& Business Media; 2011.

[29] Kim Y-I, Ko J-M, Choi S-H. Methods for generating TLPs (typical load profiles) for smart grid-based energy programs. n.d. https://doi.org/10.1109/CIASG.2011.59 53331.

[30] Kwac J, Flora J, Rajagopal R. Household energy consumption segmentation using hourly data. IEEE Trans Smart Grid 2014;5:420-30. https://doi.org/10.1109/ TSG.2013.2278477.

[31] Räsänen T, Voukantsis D, Niska H, Karatzas K, Kolehmainen M. Data-based method for creating electricity use load profiles using large amount of customer-specific hourly measured electricity use data. Appl Energy 2010. https://doi.org/10.1016/ j.apenergy.2010.05.015.

[32] Zhou K Le, Yang SL, Shen C. A review of electric load classification in smart grid environment. Renew Sustain Energy Rev 2013. https://doi.org/10.1016/j. rser.2013.03.023.

[33] Rhodes JD, Cole WJ, Upshaw CR, Edgar TF, Webber ME. Clustering analysis of residential electricity demand profiles. Appl Energy 2014;135:461-71. https://doi org/10.1016/j.apenergy.2014.08.111.

[34] Hafez AZ, Soliman A, El-Metwally KA, Ismail IM. Tilt and azimuth angles in solar energy applications - a review. Renew Sustain Energy Rev 2017;77:147-68. https://doi.org/10.1016/j.rser.2017.03.131.

[35] ABB. ABB central inverters - PVS800, 100 to 500 kW. 2011.

[36] Maghami MR, Hizam H, Gomes C, Radzi MA, Rezadad MI, Hajighorbani S. Power loss due to soiling on solar panel: a review. Renew Sustain Energy Rev 2016. https://doi.org/10.1016/j.rser.2016.01.044.

[37] Leloux J, Narvarte L, Trebosc D. Review of the performance of residential PV systems in Belgium. Renew Sustain Energy Rev 2012. https://doi.org/10.1016/j. rser.2011.07.145.

[38] Mirzaei PA, Olsthoorn D, Torjan M, Haghighat F. Urban neighborhood characteristics influence on a building indoor environment. Sustain Cities Soc 2015. https://doi.org/10.1016/j.scs.2015.07.008.

[39] Yingli Solar. Raise the roof on performance. 2011.

[40] Campana PE, Holmberg A, Pettersson O, Klintenberg P, Hangula A, Araoz FB, et al. An open-source optimization tool for solar home systems: a case study in Namibia. Energy Convers Manag 2016. https://doi.org/10.1016/j.enconman.2016.10.003.

[41] Hosseini-Fashami F, Motevali A, Nabavi-Pelesaraei A, Hashemi SJ, Chau K wing. Energy-Life cycle assessment on applying solar technologies for greenhouse strawberry production. Renew Sustain Energy Rev 2019. https://doi.org/10.1016/ j.rser.2019.109411.

[42] SolarTRIZ. The list of 76 banks with solar photovoltaic loan services in China 2017 (accessed April 2, 2020), https://news.solarbe.com/201706/22/115152.html.
[43] China Photovoltaic Industry Association. China PV industry development roadmap. 2020. accessed, http://www.chinapv.org.cn/road_map.html. [Accessed 2 April 2020].

[44] Internaional Energy Agency (IEA). reportPhotovoltaic power systems Programme (PVPS) annual report (2000-2018). n.d.

[45] Yuan J, Na C, Lei Q, Xiong M, Guo J, Hu Z. Coal use for power generation in China. Resour Conserv Recycl 2018. https://doi.org/10.1016/j.resconrec.2016.03.021.

[46] Gimon E, O’Boyle M, Clack CTM, McKee S. The coal cost crossover: economic viability of existing coal compared to new local wind and solar resources. Energy Innov 2019;24.

[47] Ma EWM, Chow TWS. A new shifting grid clustering algorithm. Pattern Recogn 2004. https://doi.org/10.1016/j.patcog.2003.08.014.

[48] Anderberg MR. Cluster analysis for applications (No. OAS-TR-73-9). Off Assist Study Support Kirtl AFB n Mex; 1973.

[49] Kaya Gülağız F, Șahin S. Comparison of hierarchical and non-hierarchical clustering algorithms. Int J Comput Eng Inf Technol 2017;9:6-14.

[50] MacQueen J. Some methods for classification and analysis of multivariate observations1. Oakland, CA, USA: Math. Stat. Probab.; 1967. p. 281-97. Proc. fifth Berkeley Symp.

[51] Das N. Hedge Fund classification using K-means clustering Method. 9th. Int Conf Comput 2003;1-27.

[52] Su M-C, Chou C-H. A modified version of the K-means algorithm with a distance based on cluster symmetry. IEEE Trans Pattern Anal Mach Intell 2001;23:674-80. https://doi.org/10.1109/34.927466.

[53] Dudley B. BP statistical review of world energy6. UK: BP Stat Rev London; 2018. p. 2018. Accessed 8.

[54] Energy Information Administration U. Electric power monthly with data for january 2020. 2019.

[55] OECD. OECD. Exchange rates (indicator). OECD 2018. https://doi.org/10.1787/ 037ed317-en. Exchange rates (indicator).

[56] Tang N, Zhang Y, Niu Y, Du X. Solar energy curtailment in China: status quo, reasons and solutions. Renew Sustain Energy Rev 2018;97:509-28. https://doi. org/10.1016/j.rser.2018.07.021.

[57] He C, Wei YHD, Pan F. Geographical concentration of manufacturing industries in China: the importance of spatial and industrial scales. Eurasian Geogr Econ 2007; 48:603-25. https://doi.org/10.2747/1538-7216.48.5.603.

[58] Zhang S, Andrews-Speed P, Li S. To what extent will China's ongoing electricity market reforms assist the integration of renewable energy? Energy Pol 2018. https://doi.org/10.1016/j.enpol.2017.12.002.

[59] Li Y, Zhang Q, Wang G, McLellan B, Liu XF, Wang L. A review of photovoltaic poverty alleviation projects in China: current status, challenge and policy recommendations. Renew Sustain Energy Rev 2018;94:214-23. https://doi.org/ 10.1016/j.rser.2018.06.012.

[60] Luthander R, Widén J, Nilsson D, Palm J. Photovoltaic self-consumption in buildings: a review. Appl Energy 2015;142:80-94. https://doi.org/10.1016/j. apenergy.2014.12.028.

[61] Kästel P, Gilroy-Scott B. Economics of pooling small local electricity prosumers LCOE \& self-consumption. Renew Sustain Energy Rev 2015;51:718-29. https:// doi.org/10.1016/j.rser.2015.06.057.

[62] Creutzig F, Agoston P, Goldschmidt JC, Luderer G, Nemet G, Pietzcker RC. The underestimated potential of solar energy to mitigate climate change. Nat Energy 2017;2:17140.

[63] Denholm P, Clark K, O'Connell M. On the path to sunshot: emerging issues and challenges in integrating high levels of solar into the electrical generation and transmission system, vol. 68; 2016. https://doi.org/10.2172/1344204.

[64] Merei G, Moshövel J, Magnor D, Sauer DU. Optimization of self-consumption and techno-economic analysis of PV-battery systems in commercial applications. Appl Energy 2016. https://doi.org/10.1016/j.apenergy.2016.01.083.

[65] Sivaram V, Kann S. Solar power needs a more ambitious cost target. Nat Energy 2016;1:1-3. https://doi.org/10.1038/nenergy.2016.36.

[66] Heptonstall P, Gross R. The EU referendum : implications for UK Energy Policy the costs and impacts of intermittency - 2016 update electricity generation technologies. 2017.

[67] National Development, Reform Commission, National Energy Administration. Notice on piloting market-based trading for distributed power generation. 2017 accessed, http://zfxxgk.nea.gov.cn/auto87/201711/t20171113_3055.htm. [Accessed 3 April 2020].

[68] Ekman P, Röndell J, Yang Y. Exploring smart cities and market transformations from a service-dominant logic perspective. Sustain Cities Soc 2019. https://doi. org/10.1016/j.scs.2019.101731. 